Measurements, Instruments, Scales, and Tests

\title{
The Addiction Severity Index: Reliability and Validity in a Dutch Alcoholic Population
}

\author{
Cor A. J. DeJong, Ph.D., M.D., ${ }^{1, *}$ Johannes C. E. W. Willems, \\ M.A., ${ }^{2}$ Gerard M. Schippers, Ph.D., ${ }^{2}$ and Vincent M. Hendriks, \\ Ph.D. ${ }^{3}$
}

'Roder Heyde Institute for Addiction Treatment Brabant, Sint Oedenrode, The Netherlands 2Department of Clinical Psychology, University of Nijmegen, Nijmegen, The Netherlands

${ }^{3}$ European Addiction Research Institute (IVO), Erasmus University, Rotterdam, The Netheriands

\begin{abstract}
The Addiction Severity Index (ASI) was evaluated for its psychometric qualities in a Dutch alcoholic population admitted to an addiction treatment center in The Netherlands. Its factorial structure in this population was found to be consistent with the established six factor structure of the ASI. Reliability analysis revealed that the homogeneity of the subscales was acceptable with the exception of the Alcohol Scale. The six subscales were not highly intercorrelated. The results of this study indicate that the ASI is a useful instrument for the assessment of several problems associated with alcoholism. However, the Alcohol Scale appears to be limited as a diagnostic and research instrument in the field of inpatient treatment of alcohol dependence in The Netherlands.
\end{abstract}

\footnotetext{
*To whom requests for reprints should be addressed at Roder Heyde Institute for Addiction Treatment, Schijndelseweg 46, 5491 TB Sint Oedenrode, The Netherlands.
} 
Key words. Addiction Severity Index; Reliability; Validity; Alcoholic inpatients

\section{INTRODUCTION}

The Addiction Severity Index (ASI) was introduced in 1979 as a comprehensive clinical and research instrument designed to assess problems in alcohol- and drug-dependent persons (McLellan et al., 1980). Evaluations of the ASI have indicated that the instrument has acceptable reliability and validity (Hodgins and El-Guebaly, 1992; Hendriks et al., 1989; McLellan et al., 1985a; McLellan et al., 1980). The aim of this study is to evaluate some aspects of reliability and validity in a homogeneous population of Dutch alcoholics seeking inpatient treatment. This study was particularly concerned with the dimensional structure, internal consistency, and distinctiveness of the subscales, as well as the concurrent validity of the Psychiatric Scale in an alcoholic inpatient population

\section{METHODS}

\section{Subjects}

The 144 subjects were patients admitted to the diagnostic unit of the Institute for Addiction Treatment, a center for the clinical treatment of drug and alcohol addicts. It is located in Brabant, The Netherlands. One hundred and one $(70.1 \%)$ of the 144 subjects were male, 43 female $(29.9 \%)$. Fifty-one subjects (35.4\%) were married, 51 (35.4\%) unmarried, 41 (28.5\%) divorced, and the marital status of $1(0.7 \%)$ was unknown. During the 6 months prior to treatment, $49(34 \%)$ had been employed, $29(20.1 \%)$ were unemployed, 47 (32.6\%) were disabled, $5(3.5 \%)$ were students, and $14(9.7 \%)$ had another employment status. Eight subjects (5.6\%) reported regular (poly)drug use. All subjects $(n=144)$ met the DSM-III-R criteria for a diagnosis of alcohol dependence (American Psychiatric Association, 1987). The average age of onset of regular alcohol use was 23.8 years $(S D=8.0$ ), and the average number of years of regular use was $12.2(\mathrm{SD}=8.1)$.

\section{Procedure and Instruments}

The Addiction Severity Index (ASI) (McLellan et al., 1980) is a semistructured clinical research interview which takes approximately 40 minutes to administer. It is designed to collect data about several areas of functioning: medical health, employment, alcohol and drug use, illegal activity, family and social relations, and psychiatric problems. 
In each of the areas, several questions are asked to assess the number, extent, and duration of the symptoms for both the client's lifetime and past 30 days. In addition, the patient is asked to subjectively rate the recent severity and importance of every problem area. For each area, the interviewer estimates the problem severity on a 10-point rating scale (0-9).

It was administered 1 to 4 weeks prior to admission by one of three experienced staff members who had been trained in interviewing alcoholic patients admitted to the treatment center.

The Symptom Check List 90 (SCL-90) (Arrindell and Ettema, 1981; Derogatis et al., 1974) is a multidimensional self-rating scale that measures the general level of psychological functioning. It was designed to assess psychological symptomatology in psychiatric and medical patients. The total score, which was used in this study, is a widely used and accepted measure of psychopathology (Koeter et al., 1988).

The SCL-90 was administered in the third week after admission. If the subject was intoxicated at referral, administration of the ASI was delayed 1 week.

\section{RESULTS}

\section{DImensional Structure of the ASI}

Factor analysis with varimax rotation on the scores of the need for help by the patient and of the severity by the patient and the interviewer (see Table 1) indicate that the Social Problems Scale is divided into family and social problems, therefore producing seven instead of six factors. For each subscale, both the two subjective scores and severity rating were used in the analysis. The seven factors explain more than $76 \%$ of the variance.

\section{Table 1.}

The Dimensiona/ Structure of ASI Scores (subject and interviewer ratings) with a Dutch Alcoholic Population ( $n=144$ ) Using a Factor with Varimax Rotation

\begin{tabular}{lccc}
\hline Factor & Eigenvalue & $\begin{array}{c}\text { Proportion of } \\
\text { variance }\end{array}$ & $\begin{array}{c}\text { Cumulative proportion } \\
\text { of variance }\end{array}$ \\
\hline 1 Medical & 3.83951 & 19.2 & 19.2 \\
2 Employment & 2.76255 & 13.8 & 33.0 \\
3 Legal & 2.36886 & 11.8 & 44.9 \\
4 Psychiatric & 2.15333 & 10.8 & 55.6 \\
5 Social problems & 1.64185 & 8.2 & 63.8 \\
6 Family problems & 1.40988 & 7.0 & 70.9 \\
7 Drug/alcohol & 1.10557 & 5.5 & 76.4 \\
\hline
\end{tabular}




\section{Internal Consistency of Subscales}

Following the statistical procedures performed by McLellen et al. (1985b), composite scores or subscales were constructed. Table 2 presents the alpha coefficients of the six subscales. The internal consistency of the various ASI subscales was acceptable with the exception of the Alcohol Scale (.46).

\section{Correlations among Composite Scores}

To assess the independence of the six subscales, the correlations between the composite scores of all subscales were determined. In Table 3 these correlations, the mean composite scores, and the standard deviations are shown. The intercorrelations were low, with the exception of the psychiatric score correlated with the scales for alcohol (.40), social (.33), and medical (.27) problems.

\section{Correlations among Severity Ratings}

The intercorrelations of the severity ratings were calculated to determine the extent to which the problem areas were related. Table 4 presents the intercorrelations plus the mean values and standard deviations of the severity ratings. All correlations among the severity ratings are relatively low. This finding suggests that the six problem areas are relatively independent from one

Table 2.

Internal Consistency of ASI Subscales with a Dutch Alcoholic Population ( $n=144$ ) Using a Bootstrapping Procedure to Obtain Cronbach's Alpha Coefficient

\begin{tabular}{lcc}
\hline Problem area & Alpha $^{\mathrm{a}}$ & $\begin{array}{c}\text { Hypothetical } \\
\text { alpha }^{\mathrm{b}}\end{array}$ \\
\hline Medical & .73 & .76 \\
Employment & .68 & .62 \\
Alcohol & .46 & .61 \\
Legal & .70 & .77 \\
Social & .78 & .79 \\
Psychiatric & .80 & .84 \\
\hline
\end{tabular}

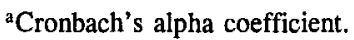

${ }^{\mathrm{b}}$ Hypothetical alpha coefficient with standardized scale length of 10 items (Spearman-Brown correction). 
Table 3.

The Relationship between ASI Composite Scores for a Dutch Alcoholic Population ( $n=144$ ). Values Represent Pearson Product-Moment Correlations

\begin{tabular}{lccccccc}
\hline & & & \multicolumn{5}{c}{ Composite score } \\
\cline { 6 - 8 } Scomposite & Mean & $(\mathrm{SD})$ & Employment & Alcohol & Legal & Social & Psychiatric \\
\hline Medical & .52 & $(0.19)$ & .17 & .19 & .06 & .01 & $.27^{*}$ \\
Employment & .57 & $(0.22)$ & & .16 & .12 & .21 & .10 \\
Alcohol & .79 & $(0.18)$ & & & -.15 & .18 & $.40^{* *}$ \\
Legal & .18 & $(0.11)$ & & & & -.12 & -.03 \\
Social & .68 & $(0.40)$ & & & & & $.33^{*}$ \\
Psychiatric & .75 & $(0.12)$ & & & & & \\
\hline
\end{tabular}

$*_{p}<.01$.

$* * p<.001$.

another, which is in accordance with the results of prior American and Dutch studies (McLellan et al., 1985a; Hendriks et al., 1989). The alcohol severity ratings did not show much variation in this sample of alcoholics $(\mathrm{SD}=0.83)$. About half of the subjects scored 7 (range 5-9). The other 50\% had scores of 6 or 8 ; very few subjects scored 5 or 9 .

\section{Correlations among Composite Scores and Severity Ratings}

To test the relation between the composite scores and severity ratings, correlation analyses were performed. The composite scores of the Medical, Employment, Legal, and Psychiatric scales showed the highest correlation with

Table 4.

The Relationship between ASI Severity Ratings in a Dutch Alcoholic Population $(n=144)$. Values Represent Pearson Product-Moment Correlations

\begin{tabular}{lccccccc}
\hline \multirow{2}{*}{$\begin{array}{l}\text { Severity } \\
\text { rating }\end{array}$} & & & \multicolumn{5}{c}{ Severity rating } \\
\cline { 6 - 9 } & Mean & $(\mathrm{SD})$ & Employment & Alcohol & Legal & Social & Psychiatric \\
\hline Medical & 1.6 & $(2.1)$ & .17 & .05 & .00 & -.01 & $.25^{*}$ \\
Employment & 2.6 & $(0.41)$ & & -.04 & .13 & .06 & -.00 \\
Alcohol & 7.1 & $(0.83)$ & & & -.13 & -.09 & .07 \\
Legal & 0.5 & $(1.3)$ & & & & .13 & .04 \\
Social & 4.1 & $(2.2)$ & & & & & $.24^{*}$ \\
Psychiatric & 4.0 & $(2.3)$ & & & & & \\
\hline
\end{tabular}

${ }^{*} p<.01$. 
Table 5.

The Relationship between ASI Severity Ratings and Composite Scores in a Dutch Alcoholic Population $(n=144)$. Values Represent Pearson Product-Moment Correlations

\begin{tabular}{lcccccc}
\hline \multirow{2}{*}{$\begin{array}{l}\text { Severity } \\
\text { rating }\end{array}$} & Medical & Employment & Alcohol & Legal & Social & Psychiatric \\
\cline { 2 - 7 } & $.74^{* *}$ & .18 & .10 & -.05 & .06 & $.30^{* *}$ \\
\hline Medical & .06 & $.72^{* *}$ & .20 & .05 & .18 & -.00 \\
Employment & .11 & -.06 & .03 & -.01 & -.21 & -.14 \\
Alcohol & -.07 & .08 & -.15 & $.81^{* *}$ & -.12 & -.06 \\
Legal & -.14 & -.01 & .11 & -.12 & .21 & $.23^{*}$ \\
Social & $.22^{*}$ & .08 & $.28^{*}$ & -.02 & .09 & $.64^{* *}$ \\
Psychiatric & & & & & & \\
\hline${ }^{*} p<.01$. & & & & & &
\end{tabular}

their corresponding severity rating. No significant correlation was obtained between the social and alcohol composite scores and the corresponding severity ratings (see Table 5).

\section{Correlations among Severity Ratings and Subscale Items}

The six areas were considered independent from one another if the correlations between the severity rating and items within each subscale were higher than the correlations between the severity rating and the items of the other subscales. None of the correlations between the severity ratings and items of other subscales appeared to be significant. In Table 6 the correlations between the severity ratings and the items within each subscale are presented. With the

Table 6.

Degree of Association between ASI Subscale Items and Severity Ratings for a Dutch Alcoholic Population $(n=144)$. Values represent Pearson Product-Moment Correlations (r)

\begin{tabular}{lc}
\hline Subscale/item & $r$ \\
\hline Medical: & \\
Number of hospitalizations, lifetime & $.27^{* *}$ \\
Chronic medical problems & $.49^{* *}$ \\
Days experiencing problems, previous month & $.44^{* *}$ \\
In treatment, past 6 months & $.36^{* *}$ \\
Worried about medical problems & $.60^{* *}$ \\
Treatment need, medical problems & $.70^{* *}$ \\
\hline
\end{tabular}


Table 6. Continued

\begin{tabular}{|c|c|}
\hline Subscale/item & $r$ \\
\hline \multicolumn{2}{|l|}{ Employment: } \\
\hline Years of education & -.15 \\
\hline Longest employment period, lifetime & -.07 \\
\hline Contribution to expenses, livelihood & $.20^{*}$ \\
\hline Days experiencing problems, previous month & $.54 * *$ \\
\hline Worried about employment problems & $.69 * *$ \\
\hline Treatment need, employment problems & $.74 * *$ \\
\hline \multicolumn{2}{|l|}{ Alcohol: } \\
\hline Years of regular alcohol use in large amounts & .14 \\
\hline Days alcohol use in large amounts, previous month & .19 \\
\hline Money spent on alcohol, previous month & .04 \\
\hline Times delirium, lifetime & .06 \\
\hline Days experiencing problems, previous month & .11 \\
\hline Worried about alcohol problems & -.08 \\
\hline Treatment need, alcohol problems & -.09 \\
\hline \multicolumn{2}{|l|}{ Legal: } \\
\hline Times arrested for property offences & $.38 * *$ \\
\hline Times arrested for violent offences & $.39 * *$ \\
\hline Times arrested for other offences & $.26^{*}$ \\
\hline Weeks of detention for property offences & $.40 * *$ \\
\hline Weeks of detention for violent offences & $.34 * *$ \\
\hline Presently awaiting a charge or sentence & $.61 * *$ \\
\hline Worried about legal problems & $.61^{* *}$ \\
\hline Treatment need, legal problems & $.78^{* *}$ \\
\hline \multicolumn{2}{|l|}{ Social: } \\
\hline Number of close friends & .02 \\
\hline Serious problems with family, lifetime & .17 \\
\hline Serious problems with friends, lifetime & $.20^{*}$ \\
\hline Serious problems with family, previous month & .14 \\
\hline Serious problems with friends, previous month & .07 \\
\hline Worried about problems with family & $.37 * *$ \\
\hline Worried about problems with friends & $.37 * *$ \\
\hline Treatment need, problems with family & $.38 * *$ \\
\hline Treatment need, problems with friends & $.42 * *$ \\
\hline \multicolumn{2}{|l|}{ Psychiatric: } \\
\hline Times treated, lifetime & $.25^{*}$ \\
\hline Depressive mood, lifetime & $.27 * *$ \\
\hline Depressive mood, previous month & $.28 * *$ \\
\hline Depressive during interview & $.43^{* *}$ \\
\hline Suicide attempts, lifetime & $.25 *$ \\
\hline Days of psychiatric problems, previous month & $.35 * *$ \\
\hline Concentration problems, previous month & $.31^{* *}$ \\
\hline Feelings of anxiety, previous month & $.36 * *$ \\
\hline Worried about psychiatric problems & $.43 * *$ \\
\hline Treatment need, psychiatric problems & $.46^{* *}$ \\
\hline
\end{tabular}

${ }^{*} p<.01$.

$* * p<.001$. 
exception of the Alcohol Scale, the results of these analyses indicated that the remaining subscales met this criterion for independence.

To assess the percentage of explained variance for each subscale, a regression analysis was performed (Table 7). All items of each subscale were used as independent variables and the severity ratings as dependent variables.

For each problem area, with exception of the Alcohol Scale, most of the variance was explained by the same item in the equation: need for treatment. This finding indicates that the severity rating by the interviewer is, to a large part, determined by the subjective report for treatment need by the patient.

Table 7.

Successive Total Proportion of Explained Variance by ASI Subscale Items for a Dutch Alcoholic Population $(n=144)$. Values Represent Cumulative $R^{2}$ Obtained from a Stepwise Regression Analysis

\begin{tabular}{ll}
\hline Subscale/item & Cumulative $r^{2}$ \\
\hline Medical: & \\
Need for treatment & .49 \\
Chronic medical problems & .53 \\
Number of hospitalizations, lifetime & .55 \\
Undergoing medical treatment, previous 6 months & .56 \\
Employment: & \\
Need for treatment & .55 \\
Worried about employment problems & .58 \\
Contribution in expenses livelihood & .59 \\
Years of education & .59 \\
Longest employment period, lifetime & .60 \\
Alcohol: & .03 \\
Days of alcohol use in large amounts, previous month & .05 \\
Years of regular alcohol use & .07 \\
Age of onset of regular alcohol use & .08 \\
Longest period clean & \\
Legal: & .61 \\
Need for treatment & .70 \\
Times arrested for violent offences & .72 \\
Presently awaiting a charge or sentence & .74 \\
Worried about legal problems & .75 \\
Weeks of detention for violent offences & \\
Social: & .17 \\
Need for treatment, social problems & .24 \\
Need for treatment, family problems & .29 \\
Problems with partner & .31 \\
Duration living situation, previous 6 months & .33 \\
Satisfaction with current living situation & \\
\hline
\end{tabular}


Table 7. Continued

\begin{tabular}{lc}
\hline Subscale/item & Cumulative $r^{2}$ \\
\hline Serious problems with others, lifetime & .34 \\
Serious problems with friends, previous month & .36 \\
Serious problems with friends, lifetime & .41 \\
Psychiatric: & \\
Need for treatment & .21 \\
Depressive during interview & .33 \\
Times treated & .36 \\
Problems with aggression control, lifetime & .38 \\
Anxiety, previous month & .39 \\
Hallucinations, lifetime & .40 \\
Suicide attempts, previous month & .41 \\
\hline
\end{tabular}

\section{Concurrent Validity of the ASI Psychiatric Severity Rating}

To obtain an indication of the concurrent validity of the ASI psychiatric severity rating, the SCL-90 total scores were correlated with the ASI Psychiatric Scale. All but the SCL-90 subscales of "insufficiency," "hostility," and "interpersonal sensitivity" were significantly correlated with the psychiatric severity score. The psychiatric severity rating was modestly correlated with the SCL-90 total score (.33). The depression subscale showed the highest correlation (.34), followed by the anxiety (.33), somatization (.29), and the agoraphobic subscales (.28).

To measure differences between SCL-90 total scores and the psychiatric severity ratings, an analysis of variance was performed. Subjects were assigned to three groups according to severity rating: (1) $0-2$, (2) $3-6$, and (3) 7-9. ASI psychiatric severity ratings were significantly higher as a function of SCL-90 total score $(\mathrm{F}=7.8 ; p<.001)$.

\section{DISCUSSION AND CONCLUSIONS}

The present results suggest that the subscales of the ASI are relatively independent of one another. The intercorrelations among the severity ratings are low. The ASI items are more closely related to their corresponding severity ratings than to the severity ratings of other subscales. In addition, the correlations between severity ratings and composite scores within each subscale were high, whereas the correlations of composite scores and severity ratings of other subscales were low, with some exceptions. 
The psychiatric severity ratings were higher for those who had higher SCL-90 scores. However, the correlation between the psychiatric severity rating and psychoneuroticism (SCL-90 total score) was rather low (.33). Thus, the value of the psychiatric severity rating as a measure of psychological and emotional problems is limited.

For each problem area (except the Alcohol Scale) it was possible to find item combinations having fairly good internal consistency. However, item combinations were found other than those used by Hendriks et al. (1989) in their research with a Dutch drug-addict population.

In this study the Alcohol Scale was the only subscale with low validity and internal consistency. The distribution of the alcohol severity ratings, and a considerable number of items of the Alcohol Scale, were highly skewed. As a consequence of the low variation, no high item correlations could be expected. The alcohol severity rating did not correlate significantly with any of the items of the Alcohol Scale. The generalizability of our results is limited. The study was done in an inpatient population of alcoholics seeking treatment. No aspects of test-retest or interrater reliability were investigated in our study. Only the concurrent validity of the psychiatric subscale was explored. With these limitations in mind, we arrive at the following conclusions.

\section{Conclusions}

1. The internal consistency of the alcoholic subscale is low.

2. The internal consistency of the other subscales of the ASI in a Dutch alcoholic inpatient population was reasonably good.

3. The validity of the ASI in this population is moderately good. Thus, the subscales can be considered as measuring independent problem areas.

4. The concurrent validity of the psychiatric problem scale is moderate.

5. The composition of subscales derived by a bootstrapping procedure to produce acceptable internal consistencies differs significantly from those found in other populations.

\section{REFERENCES}

AMERICAN PSYCHIATRIC ASSOCIATION (1987). Diagnostic and Statistical Manual of Mental Disorders, 3rd rev. ed. Washington, D.C.: American Psychiatric Association.

ARRINDELL, W. A., and ETTEMA, H. (1981). Dimensionele structuur, betrouwbaarheid en validiteit van de Nederlandse bewerking van de Symptom Check List. [Dimensional structure, reliability and validity of the Dutch version of the Symptom Check List.] Ned. Tijdschr. Psychol. 36: 77-108.

DEROGATIS, L., LIPMAN, R., and RICKELS, K. (1974). The Hopkins Symptom Check List (HSCL): A self-report symptom inventory. Behav. Sci. 19: 1-16.

HENDRIKS, V. M., KAPLAN, Ch. D., LIMBEEK, J. VAN, and GEERLINGS, P. J. (1989). The 
Addiction Severity Index: Reliability and validity in a Dutch addict population. J. Substance Abuse Treatment 6: 133-141.

HODGINS, D. C., and EL-GUEBALY, N. (1992). More data on the Addiction Severity Index: Reliability and validity with the mentally ill substance abuser. J. Nerv. Ment. Dis. 180: 197-201.

KOETER, M. W. J., ORMEL, J., and BRINK, W. VAN DEN (1988). De totaal-score van de SCL90 als maat voor de ernst van de psychopathologie. [The total score of the SCL-90 as a measure for the severity of psychopathology.] Ned. Tijdschr. Psychol. 43: 381-391.

MCLELLAN, A. T., LUBORSKY, L., CACCIOLA, J., GRIFFITH, J., EVANS, F., BARR, H. L., and O'BRIEN, C. P. (1985a). New data from the Addiction Severity Index: J. Nerv. Ment. Dis. 173: 412-423.

MCLELLAN, A. T., LUBORSKY, L., CACCIOLA, J., GRIFFITH, J., MCGRAHAN, P., and O'BRIEN, C. P. (1985b). Guide to the Addiction Severity Index; Background, Administration, and Field Testing Results (National Institute on Drug Abuse, Treatment Research Monograph Series). Washington, D.C.: US Government Printing Office.

MCLELLAN, A. T., LUBORSKY, L., WOODY, G. E., and O'BRIEN, C. P. (1980). An improved diagnostic evaluation instrument for substance abuse patients: The Addiction Severity Index. J. Nerv. Ment. Dis. 168: 26-33.

\section{THE AUTHORS}

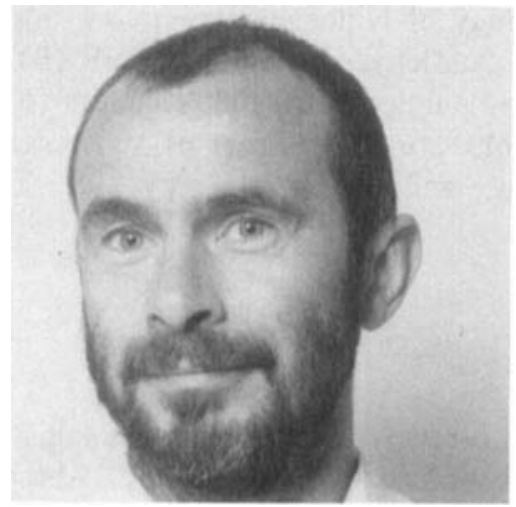

Cor A. J. DeIong, medical doctor and psychotherapist, is medical supervisor of Roder Heyde Institute for Addiction Treatment in Sint Oedenrode. His publications and articles are in the area of psychotherapy, psychiatry, personality disorders, and substance misuse. His thesis (1993) deals with the prognostic aspects of multidimensional diagnosis in alcoholic inpatients. 

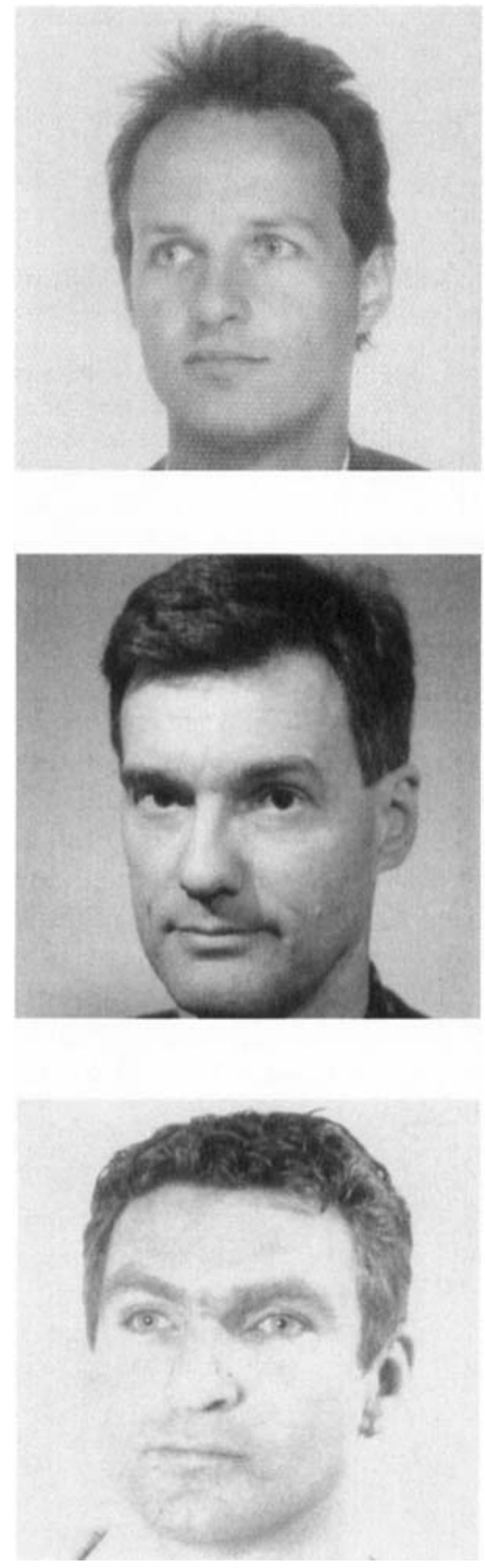

Joost C. E. W. Willems, psychologist, is at the University of Nijmegen, investigating AIDS-related problems in Dutch prisons. At the Hahnemann University in Philadelphia he studied drug-using networks of injecting drug users in the Philadelphia area. Currently he works as a psychotherapist.

Gerard M. Schippers, psychologist, is Associate Professor at the Clinical Psychology Faculty of The University of Nijmegen and director of the University of Nijmegen Research group on Addictive Behaviors (UNRAB). His publications and chapters of books are in the area of substance abuse and cognitive therapy.

Vincent M. Hendriks, psychologist, is coordinator of the Substance Abuse Research unit of the Addictive Research Institute of Erasmus University of Rotterdam. 